\title{
A Ultrassonografia Obstétrica e suas Implicações para a Relação Materno-Fetal ${ }^{1}$
}

\author{
Aline Grill Gomes \\ Cesar Augusto Piccinini \\ Universidade Federal do Rio Grande do Sul
}

\begin{abstract}
RESUMO
O objetivo desta pesquisa foi investigar as implicações emocionais da ultrassonografia obstétrica para a relação materno-fetal, no contexto de normalidade fetal. Participaram 11 gestantes primíparas, com idades entre 18 e 35 anos e idades gestacional entre 11 e 24 semanas, que estavam sendo submetidas pela primeira vez à ultrassonografia. Elas responderam a uma entrevista semiestruturada e à Escala de Apego Materno-Fetal, antes e depois do exame. Análise de conteúdo qualitativa das entrevistas mostrou que a ultrassonografia, além de modificar a visão da mãe sobre o bebê, que passou a vê-lo de uma forma mais real e concreta, intensificou os comportamentos de interação mãe-bebê, ou seja, ampliou as diferentes maneiras de interagir e fortificou os sentimentos maternos, fazendo com que a mãe se sentisse mais apropriada de seu papel. Análise estatística revelou um aumento significativo na média dos escores da escala de apego após o exame. Juntos, os resultados indicam que a ultrassonografia parece ter exercido um impacto importante nas gestantes influenciando a relação mãe-bebê.
\end{abstract}

Palavras-chave: ultrassonografia; relação materno-fetal; normalidade fetal.

\section{ABSTRACT \\ The Obstetric Ultrasound and Its Implications on Mother-Fetus Relationship}

This study aimed to investigate the emotional implications of obstetric ultrasound for the maternal-fetal relationship, in the context of fetal normality. Eleven primiparous pregnant women, aged 18 to 35 , with gestational ages between 11 and 24 weeks, who were being submitted to ultrasound for the first time, took part in the study. They answered a semi-structured interview and the Mother-Fetus Attachment Scale, before and after the examination. Qualitative content analysis of the interviews revealed that ultrasound, in addition to modifying the mother's view about the baby, now seen as more real and concrete, has intensified mother-baby interaction behaviors, expanding the different ways of contact, and strengthening maternal feelings, making the mother feel more appropriate in its role. Wilcoxon Test revealed a significant increase in mother-fetus attachment after the examination. Taken as a whole, the results indicate that ultrasound had an important emotional impact on pregnant women, influencing mother-baby relationship.

Keywords: ultrasound; mother-fetus relationship; fetal normality.

No contexto da normalidade fetal, que é o foco do presente estudo, a ultrassonografia obstétrica, além de determinar características gerais do feto e identificar gestações múltiplas, é também capaz de dirimir dúvidas quanto à saúde e o bem-estar fetal. Pode-se dizer, então, que a partir do exame ultrassonográfico introduziu-se uma nova forma de contato com o bebê, possibilitando à gestante visualizá-lo e conhecê-lo antes de seu nascimento. Esse processo introduz implicações psicológicas e sociais para toda família (Fonseca \& cols., 2000; Nicol, 2007; Quayle, Isfer \& Zugaib, 1991).

A literatura apresenta divergências quanto às repercussões da ultrassonografia para a representação materna sobre o bebê e para a relação materno-fetal. A maioria dos estudos revelou uma influência positiva da ultrassonografia na relação mãe-feto (Baillie, Mason \& Hewison, 1997; Boukydis e cols., 2006; Caccia, Johnson, Robinson \& Barna, 1991; Fletcher \& Evans, 1983; Kohn, Nelson \& Weiner, 1980; Pretorius e cols., 2006; Raphael-Leff, 1997; Sioda, 1984). Estes autores mostraram que a ultrassonografia possibilita que a gestante se apodere mais do seu papel de mãe, e perceba o feto como mais real e próximo. O exame facilitaria, então, a transição para a parentalidade, e intensificaria a união pré-natal entre mãe e feto, além de aumentar a adesão das gestantes às recomendações médicas e ocasionar um decréscimo de sua ansiedade. 
Por ser uma vivência descrita como bastante intensa e de proximidade com o bebê e com a gestação, auxiliaria no apego materno-fetal, principalmente para aquelas mães com histórias de dificuldades vinculares.

Interferências adversas da ultrassonografia também foram apontadas por algumas pesquisas (Courvoisier, 1985; Fletcher \& Evans, 1983; Piontelli, 2000; Soulé, 1987). Estes autores indicaram que a ultrassonografia traz à tona uma realidade muito precoce, fazendo com que a imagem real do feto destrua as fantasias maternas e a gestante se sinta invadida. Ademais, o exame poderia promover um choque pelo reconhecimento real do feto e provocar um sentimento de vulnerabilidade na gestante, tendo em vista que os achados ecográficos podem apresentar problemas cujas soluções não estão ao seu alcance.

Para outros autores considerando a relevância da ultrassonografia para a experiência emocional da gestante é importante que se avalie o desejo dos pais de conhecerem seu bebê antes mesmo do nascimento (Van der Zalm \& Byrne, 2006; Villeneuve, Laroche, Lippman \& Marrache, 1988). Há casais que demonstram interesse e prazer pelo conhecimento da vida fetal. No entanto, mesmo que em menor número, existem pais que preferem esperar o nascimento para se deparar com seus filhos, o que exige dos profissionais uma postura mais cautelosa com relação aos exames ecográficos e às informações gerais sobre o feto. Villeneuve e cols. acreditam, portanto, que as implicações positivas e adversas da ultrassonografia dependem, em certa medida, das expectativas internas dos pais e da capacidade do profissional de percebê-las. Ainda nesta mesma direção, Caron (2000) defende que os efeitos da ultrassonografia na experiência emocional da mãe dependerão muito da sua história passada, de suas necessidades e conflitos psíquicos, de seu momento atual de vida e de sua capacidade de elaborar as representações mentais de seu filho.

Tendo em vista o exposto acima, o presente estudo buscou investigar as implicações da ultrassonografia para a relação materno-fetal e, em particular, as impressões da gestante sobre o bebê e sobre a maternidade no contexto de normalidade fetal.

\section{MÉTODO}

\section{Participantes}

Participaram deste estudo 11 gestantes em situação de normalidade fetal. As gestantes eram primíparas, sendo que nove eram primigestas e duas já tinham tido pelo menos um aborto espontâneo. A Tabela 1 apresenta as características demográficas das participantes. As gestantes tinham idade entre 18 e 35 anos $(M=23,45 ; d p=5,56)$. A idade gestacional variou de 11 a 24 semanas de gestação $(M=15,09 ; d p=4,44)$ e todas elas estavam sendo submetidas pela primeira vez na vida à ultrassonografia obstétrica. Quanto à escolaridade, as participantes tinham ensino fundamental incompleto $(n=2)$ ou completo $(n=3)$ e as demais, ensino médio completo $(n=4)$ ou incompleto $(n=2)$, $(\mathrm{M}=9$ anos estudados; $\mathrm{dp}=2,53$ anos). Quanto à atividade profissional, quatro gestantes exerciam atividades no lar, quatro trabalhavam com serviços gerais, uma era estudante, e duas tinham atividades técnicas. Todas mantinham relacionamento estável com o pai do bebê.

TABELA 1

Dados Demográficos das Gestantes

\begin{tabular}{lllllll}
\hline Gestante & Idade & IG* & \multicolumn{1}{c}{ Paridade } & \multicolumn{1}{c}{ Escolaridade } & \multicolumn{1}{c}{ Ocupação } & Situação Marital \\
\hline G1 & 23 & 11 & Primípara* $^{*}$ & E. F. incompleto & Empregada doméstica & Mora junto há 5a \\
G2 & 20 & 13 & Primípara** $^{*}$ & E. M. completo & Sem atividade & Mora junto há 3m \\
G4 & 22 & 11 & Primigesta & E. M. completo & Sem atividade & Namora há 1a e 2m \\
G5 & 18 & 20 & Primigesta & E. M. incompleto & Estudante & Mora junto há 2a \\
G6 & 21 & 24 & Primigesta & E. M. incompleto & Serviços gerais & Noiva há 4a \\
G7 & 26 & 13 & Primigesta & E. F. incompleto & Serviços gerais & Casada há 5a \\
G8 & 33 & 20 & Primigesta & E. M. completo & Aux. administrativa & Mora junto há 3a \\
G9 & 19 & 11 & Primigesta & E. F. completo & Sem atividade & Namora há 3a e 3m \\
G10 & 18 & 15 & Primigesta & E. M. completo & Sem atividade & Namora há 1a e 2m \\
G11 & 24 & 12 & Primigesta & E. M. incompleto & Estudante/Camareira & Casada há 6a e 6m \\
\hline
\end{tabular}

Nota: \# Idade gestacional (semanas); * com um aborto espontâneo; ** com dois abortos espontâneos. 
As participantes foram recrutadas entre as que estavam sendo submetidas à ultrassonografia obstétrica no Serviço de Medicina Fetal do Hospital de Clínicas de Porto Alegre, sob a aprovação do comitê de ética desta instituição. Foram convidadas a participar do estudo todas as gestantes que preenchiam aos critérios de inclusão da amostra descritos acima e que estavam realizando o exame dentro dos 3 meses em que a pesquisadora esteve presente no hospital, para fins de coleta dos dados. Foram excluídas 2 participantes que, por motivos de mudança de cidade, não compareceram ao segundo momento de coleta de dados.

\section{Delineamento, Procedimentos e Instrumentos}

Foi utilizado um delineamento de um grupo com pré e pós-teste (Robson, 1995), buscando investigar as implicações da ultrassonografia para a relação materno-fetal e, em particular, as impressões da gestante sobre o bebê e sobre a maternidade no contexto de normalidade fetal.

Antes da entrada das gestantes para a sala de exame, elas passaram em uma antessala, onde foram convidadas a participar do estudo. O Termo de Consentimento Livre e Esclarecido (adaptado de Grupo de Interação Social, Desenvolvimento e Psicopatologia GIDEP, 1998a) foi, então, assinado e a ficha de dados demográficos (GIDEP, 1998b) preenchida pela pesquisadora, visando obter algumas características demográficas, tais como: sexo, idade, status social, estado civil, escolaridade, profissão e endereço. As gestantes foram, então, solicitadas a responder a entrevista sobre a história obstétrica da gestante (Gomes \& Donelli, 2001), que buscou obter dados da história obstétrica da gestante, tais como: paridade, história pregressa de saúde materna e fetal, intercorrências e condições clínicas gerais. Responderam também à entrevista sobre a ultrassonografia obstétrica e a relação materno-fetal (Gomes \& Piccinini, 2001), que examinou as expectativas, as impressões e os sentimentos das gestantes em relação à ultrassonografia, e suas implicações na relação mãe-feto. Por último, foi aplicada a Escala de Apego Materno-Fetal (Cranley, 1981), que objetivou medir a intensidade de apego pré-natal da mãe com o bebê. Este instrumento consta de 24 itens, divididos em cinco subescalas que representam diferentes aspectos desta relação e, para cada uma das questões, são oferecidas cinco opções de respostas em uma escala do tipo Likert. O índice de consistência interna original da escala total (Alpha de Cronbach) é 0,85 ; e o da validação brasileira (Feijó, 1999) foi de 0,63 .
Em seguida, a pesquisadora acompanhava as gestantes para a sala onde era realizado o exame ultrassonográfico e permanecia com ela até o término deste. As ultrassonografias tiveram a duração de 15 a 30 minutos e foram realizadas por médicos ginecologistas e obstetras ou radiologistas, com especialização em ultrassonografia fetal. O equipamento utilizado para o exame foi um Aloka SSD - 1700, que reproduz uma imagem dinâmica em duas dimensões, sendo que o monitor era levemente virado para a gestante de maneira que oportunizasse a ela participar ativamente olhando as imagens. Após o término da ultrassonografia, as gestantes eram encaminhadas a uma outra sala onde era realizada novamente à entrevista sobre a ultrassonografia obstétrica e a relação materno-fetal.

Três semanas após a ultrassonografia, as gestantes retornaram ao hospital, quando foram solicitadas a responder novamente à entrevista sobre a ultrassonografia obstétrica e a relação materno-fetal e à Escala de Apego Materno-Fetal. O intervalo de três semanas para este contato foi escolhido para permitir às gestantes um período de reflexão em relação à ultrassonografia e para que as eventuais implicações na relação mãe-feto pudessem ser percebidas. Não foi considerado um intervalo de tempo maior, tendo em vista que se tinha a intenção de aplicar novamente estes instrumentos antes de qualquer outro procedimento médico, e algumas gestantes eram encaminhadas para novos exames. O tempo de duração da aplicação destes instrumentos levava em média cerca de 30 minutos, com algumas variações, de acordo com a individualidade de cada gestante.

\section{RESULTADOS}

Os resultados estão apresentados em duas partes. Na primeira, examinam-se qualitativamente os relatos das gestantes na entrevista sobre a ultrassonografia e a relação materno-fetal, realizada antes e depois do exame investigando as implicações da ultrassonografia obstétrica na relação materno-fetal, na visão da gestante sobre o bebê, e na maternidade. Na segunda parte, examinam-se os escores das gestantes na Escala de Apego Materno-Fetal, investigando o apego materno-fetal antes e depois do exame. Por fim, ao término dos resultados das duas partes, apresenta-se uma discussão dos principais resultados, com base na literatura e na experiência pessoal da autora. 


\section{Parte I: Implicações da ultrassonografia no contexto materno-fetal}

Análise de conteúdo qualitativa (Laville \& Dione, 1999) foi utilizada para classificar as respostas das mães, com base numa estrutura de três eixos temáticos exemplificados a seguir. Para fins de análise, duas psicólogas classificaram separadamente as respostas e, em casos de discordância, utilizou-se uma terceira psicóloga. É importante salientar que o critério para a inclusão das verbalizações nos momentos citados (antes, logo após ou três semanas depois do exame) baseou-se na referência das próprias gestantes ao momento que tinham sentido e/ou pensado determinado conteúdo e não necessariamente no momento cronológico em que foram coletados os dados.

Com base na leitura exaustiva das entrevistas, na experiência da pesquisadora e na literatura, foram criados três eixos temáticos. O primeiro deles, denominado Impressões e sentimentos das gestantes sobre $o$ bebê, referiu-se a como o bebê foi percebido na ultrassonografia e aos efeitos do exame na visão da gestante sobre o bebê ao longo do período investigado. $\mathrm{O}$ segundo, denominado Impressões e sentimentos das gestantes sobre a relação mãe-bebê, englobou os sentimentos das gestantes em relação ao bebê, os meios utilizados pelas gestantes para interagir com o bebê e as possíveis interferências da ultrassonografia nesta relação. Por fim, o terceiro e último eixo, denominado Impressões e sentimentos das gestantes sobre a maternidade, examinou os sentimentos de maternidade expressos pelas gestantes e às possíveis repercussões da ultrassonografia na identidade materna.

Apresentam-se, a seguir, os resultados desta análise, com breve descrição de cada eixo temático, exemplificando-as com trechos de relatos das próprias gestantes.

\section{Impressões e Sentimentos das Gestantes sobre o Bebê}

Antes do exame, as gestantes referiram impressões de um bebê em desenvolvimento muito inicial: "eu fico imaginando ele todo transparente, pequeninho" $\left(G 2,13^{a} s\right)$. Imaginaram o bebê através de características físicas: "ah eu descreveria que ele seria assim parecido com o pai dele" (G6, 26as), e emocionais "de personalidade eu acho que ele vai ser quietinho" (G5, 24 semanas). Já no que concerne aos sentimentos em relação ao bebê antes do exame, as gestantes expressaram incertezas quanto ao número de bebês estavam gestando: "com medo de não ser um só também, de ser dois" $\left(G 2,13^{a} s\right)$ e medo de que o bebê portasse algum tipo de anormalidade: "eu tinha medo (...) que ele não fosse perfeito, que ele não tivesse um bracinho, uma perninha" $\left(G 5,24^{a} s\right)$. Houve também gestantes que nunca imaginaram quaisquer dados a respeito do bebê: "eu não tava acreditando ainda muito" $\left(G 8,9^{a} s\right)$, nem mesmo através de desejos e/ou pensamentos fantasiosos.

Quanto às impressões maternas sobre o bebê durante e depois do exame, pode-se perceber as influências da ultrassonografia. Não houve mais quaisquer relatos de dúvida quanto à existência real do bebê, nem verbalizações expressando impossibilidade de imaginar dados acerca do bebê, como ocorreu antes do exame. Ao contrário, as gestantes expressaram a ideia de um bebê mais concreto e real: "antes parecia que não era real, agora é real, (...) então agora mudou (...) eu não tava acreditando ainda muito" (G8, $11^{a} \mathrm{~s}$ ), e também bem mais desenvolvido do que elas imaginavam: "eu achava que não era formado, que já tinha a cabeça" $\left(G 3,11^{a} \mathrm{~s}\right)$. As impressões sobre o bebê se deram, novamente, através de algumas características emocionais, imaginadas através dos movimentos do bebê durante o exame e também características físicas, sendo estas percebidas na imagem do monitor de ultrassonografia: "ah o que eu vi assim, que eu achei, eu olhei pra ele e achei ele parecido comigo" $\left(G 2,13^{a} s\right)$.

Os sentimentos em relação ao bebê durante e depois do exame evidenciaram que os dados fornecidos pela ultrassonografia serviram para que algumas gestantes se sentissem satisfeitas e esclarecidas a respeito do bebê: "eu tô sentindo que ficou mais claro pra mim né, porque antes eu não tinha visto nada e não tava claro pra mim" $\left(G 9,15^{a} s\right)$, enquanto outras mães demonstraram curiosidade em saber outros detalhes sobre o filho, numa tentativa de uma visão ainda mais completa: "fiquei com aquela vontade de querer clarear mais, queria ver mais, gostei de estar vendo!" (G1, $\left.11^{a} \mathrm{~s}\right)$.

Depois de três semanas, as impressões foram de um bebê ainda mais concreto e real, dono, inclusive, de uma autonomia própria, podendo, por exemplo, expressar suas próprias vontades: "fez assim com o dedinho assim, como se dissesse - pára de mexer a barriga da mãe" $\left(G 6,13^{a}\right.$ s), e até poderoso para interferir nos seus gostos e hábitos das gestantes: "sou apaixonada por churrasco e agora eu não suporto mais carne" $\left(G 2,13^{a} s\right)$. Ademais, as gestantes referiram imaginar um bebê mais desenvolvido do que três semanas atrás, expressando a ideia de continuidade do crescimento do bebê: "eu imagino que ele já tá mais um pouquinho mais grandezinho né, ah já é quase perfeitinho assim" $\left(G 8,11^{a} \mathrm{~s}\right)$. 
As gestantes também falaram sobre o bebê com base nas características físicas dele, as quais apareceram ligadas a uma mescla de dados reais, observados nas imagens da ultrassonografia: "bem parecidinho comigo, narizudinho" $\left(G 1,11^{a} s\right)$, com dados imaginários, provenientes das fantasias e dos desejos das gestantes: "mas eu acho que ela vai ser parecida com o pai dela, eu não sei eu vi o pai dela ali no monitor. (...) ah eu ia gostar porque ele é bonito" $\left(G 6,13^{a}\right.$ s). A mesma mescla de dados reais e fantasiosos também apareceu relacionada às características emocionais: " $e$ eu acho que na minha barriga ela é calminha (...) vai ser calminha assim (...) eu espero que a minha filha seja assim" (G5, 24 ${ }^{a}$ s).

Os sentimentos em relação ao bebê três semanas depois do exame envolveram, por um lado, a certeza de que o bebê estava bem: "agora eu sei que tá tudo bem né" $\left(G 8,11^{a} s\right)$ e, por outro, a permanência de dúvidas sobre suas condições de saúde: "eu rezo todas as noites que ele seja perfeitinho" $\left(G 1,11^{a} s\right)$. Apareceu também um sentimento de curiosidade em saber mais detalhes do bebê, expressando que o tempo transcorrido lhes deixou pensando em novas informações: "eu to tri assim ansiosa para saber se é menino ou menina (...) eu quero saber o que é” $\left(G 9,15^{a} s\right)$.

\section{Impressões e Sentimentos sobre a Relação Mãe-Bebê}

Dentre os modelos de relação mãe-bebê identificados nas falas das gestantes antes do exame, destacam-se verbalizações referindo-se à falta de contato: "relação com ele? [bebê] sinceramente eu não sei se é porque eu não senti ele aqui dentro, parece que ainda não tem nada aqui dentro, só um carocinho assim" $\left(G 2,13^{a} s\right)$ ", e/ou um contato relativamente vago e pouco definido: "normal, normal, como todas as mães sentem" $\left(G 1,11^{a} \mathrm{~s}\right)$, além de outras que falaram da relação reportando-se ao futuro: "fico me imaginando com ele nos braços" (G4,20 $\mathrm{s}$ ), expressando, com isso, que o modelo relacional no momento era baseado em imaginações, em conjecturas para depois do nascimento do bebê.

Uma perspectiva de relação mãe-bebê um pouco mais presente apareceu através da postura de cuidado de algumas gestantes consigo mesmas. Por fim, foram citadas formas de interação mais diretamente dirigidas ao bebê, as quais envolveram desde o comportamento de tocar a barriga, conversar com o bebê, perceber seus movimentos: "quando ele chuta, eu pergunto se ele tá com fome" $\left(G 5,24^{a} s\right)$, até o ato de pensar nele: "acho que a maioria do tempo eu fico pensando mais nele do que em mim mesma” (G4, 20 $\left.{ }^{a} \mathrm{~s}\right)$.
Durante e após o exame as mães relataram um surgimento e/ou intensificação dos sentimentos de afeto pelo bebê: "ah eu comecei a gostar mais né (...) acho que está diferente!" (G3, 11 $\mathrm{a}$ s), e/ou de posse "feliz porque é um fruto meu, uma coisa que eu vou cuidar e criar do meu jeito e ninguém vai poder se meter, uma coisa que é só minha, ninguém mais me tira!'(G10, $\left.12^{\mathrm{a}} \mathrm{s}\right)$. Logo em seguida da ultrassonografia, algumas gestantes manifestaram sua intenção de intensificar os cuidados que estavam tendo consigo mesmas e com a gravidez: "ah, agora mudou tudo, agora eu vou me cuidar pra não machucar ele né (...) tem que cuidar $n e^{\prime \prime}\left(\mathrm{G} 6,13^{\mathrm{a}} \mathrm{s}\right)$.

Três semanas após o exame, as gestantes referiram que durante esse período se tornaram ainda mais conscientes sobre a necessidade de iniciar e/ou mesmo intensificar seus cuidados consigo mesmas e com a gravidez: "ah mudou em tudo né as coisas que eu fazia agora não tô fazendo mais pra não prejudicar ele né" $\left(G 6,13^{a} s\right)$, acreditando que desta forma estariam também cuidando do bebê. As participantes passaram a perceber, neste período, uma intensificação também dos sentimentos de afeto pelo bebê: "mudou muita coisa, eu fiquei apaixonada por ele" (G2, $\left.13^{a} s\right)$, bem como do contato estabelecido com ele, fosse por meio das conversas ou do comportamento de tocar a barriga, que se tornaram mais frequentes ou foram iniciados no decorrer desse período. Essa maior proximidade foi diretamente atribuída, por algumas gestantes, a estarem agora mais cientes da concretização da gravidez e da existência do bebê: "até a eco assim tu pode conversar, mas depois da eco, daí sim tu sabe que pode conversar, que a criança tá ali mesmo, daí tu conversa e tu sabe que existe" $\left(G 11,13^{a} s\right)$.

A ultrassonografia apareceu como uma via de contato com o bebê, seja para favorecer que as gestantes lembrassem melhor e pensassem mais no bebê: "lembro dele e aí vem aquela imagem assim, sempre quando eu lembro a primeira imagem que vem é como eu vi ele ali né (...) quando eu tô conversando eu imagino aquelas fotos, é o que vem na minha cabeça" $\left(G 8,11^{a} s\right)$, seja para lhes assegurar que a saúde do bebê continuava em boas condições: "agora a gente fica preocupada de novo, não sabe como é que ele tá de novo né, ah pra ouvir o batimento cardíaco só eu vou ter que fazer de novo a ecografia" $\left(G 6,13^{a} \mathrm{~s}\right)$.

Contudo, apareceram também relatos expressando não influência do exame na sua forma de relação com o bebê: "não mudou" (G3, 11 $\left.{ }^{\mathrm{a}} \mathrm{s}\right)$; "ah, eu passo a maior parte do tempo conversando com ele, cuidando das coisinhas dele ou dela (...) eu pego passo a mão na barriga (...) não mudou" (G4, 20ª s), expressando não 
terem percebido diferenças significativas entre seu comportamento com o bebê antes e depois da ultrassonografia.

\section{Impressões e Sentimentos sobre a Maternidade}

Antes do exame, quando questionadas a respeito da maternidade, pelo menos uma mãe disse que ainda não se sentia mãe $\left(\mathrm{G} 3,11^{\mathrm{a}} \mathrm{s}\right)$ enquanto que outras relataram tanto sentimentos negativos, representados, principalmente, pela preocupação em não dar conta do papel materno: "é difícil, porque a gente tem medo de não conseguir certas coisas, de não conseguir educar" (G5, 24 $\left.{ }^{a} s\right)$; como sentimentos positivos, que falaram da maternidade como algo bom de sentir, embora difícil de explicar: "ah, eu já me sinto mãe, ah eu nem sei explicar (...) mas é uma coisa boa né, que a gente sente" $\left(G 6,13^{a} \mathrm{~s}\right)$; ou ainda sentimentos ambivalentes: "é legal, só que, acho que eu não sei (...) eu fico revoltada, não me sinto bem" $\left(G 2,13^{a} s\right)$.

A maternidade foi referida tanto como ligada ao próprio bebê com um estranhamento: "mas quando me chamam de mãezinha assim parece um pouco estranho, é a primeira vez" (G5, 24 s), ou um sentimento de proteção: "é uma coisa especial, de proteção" (G7, 20 a s); como relacionada aos sintomas físicos da gravidez: "eu me sinto diferente das outras pessoas (...) as pessoas comem e eu não consigo comer" (G2, 13 $\left.{ }^{\mathrm{a}} \mathrm{s}\right)$, e/ou a experiências anteriores de cuidado com outras crianças: "me sinto mãe, tanto que eu tenho duas enteadas" (G7, 20 a s).

Durante e após o exame os sentimentos maternos apareceram como mais concretos e reais: "ah sei lá, acho que eu pensei ah existe mesmo, eu acho que vou ser mãe mesmo" (G1, 11 $\left.{ }^{\mathrm{a}} \mathrm{s}\right)$, e também mais intensos: "o sentimento eu já tinha sentido (...) mas a intensidade foi maior" (G9, 15 $\left.{ }^{\mathrm{a}} \mathrm{s}\right)$. Esse sentimento de concretização se estendeu para uma maior conscientização de que agora teriam um ser dependente delas: "eu já tava nervosa, agora eu tô mais ainda, porque eu sei que eu tenho uma filha dentro de mim, eu tenho que me cui- dar mais" (G10, 12 $\left.{ }^{\mathrm{a}} \mathrm{s}\right)$. A maternidade se fez presente também através da satisfação diante da condição feminina de gestar: "a gente se sente especial, se sente realizada em ver o nenezinho dentro da gente, é bom" $\left(\mathrm{G} 2,11^{\mathrm{a}} \mathrm{s}\right)$.

Três semanas após o exame, percebeu-se ainda mais intensificação dos sentimentos maternos: "agora eu tô me sentindo mais mãe" (G5 24 $4^{a}$ s), conscientização da responsabilidade: "a primeira coisa é pensar que não é brincadeira, que aquilo é verdade (...) isso vai evoluindo pro pensamento, antes do exame eu não tinha pensado" (G5, $24^{a}$ s), e também uma preocupação mais específica com o bebê e com o exercício do papel materno: "fiquei pensando que eu vou ser mãe (...) e que responsabilidade (...) piorei depois da ecografia, porque dai eu vi" $\left(\right.$ G10, $\left.12^{a} \mathrm{~s}\right)$.

\section{Parte II: A ultrassonografia e o apego mãe-feto}

Os escores obtidos na aplicação da Escala de Apego Materno-Fetal antes da realização da ultrassonografia e três semanas depois foram submetidos a uma análise estatística através do teste Wilcoxon para verificar existência de diferenças significativas entre os totais dos dois momentos observados ${ }^{2}$. Para a apresentação dos resultados, a significância $(p)$ será apresentada no seu valor real. O critério escolhido para significância estatística foi $\alpha=5 \%$, sendo o $p$ considerado $<0,05$.

A Tabela 2 apresenta média, desvio padrão e escores mínimos e máximos obtidos pelas participantes na Escala de Apego Materno-Fetal aplicada antes e depois da ultrassonografia. Como se pode constatar, o escore médio total obtido pelos participantes antes do exame foi menor $(\mathrm{M}=61 ; d p=7,8)$ do que três semanas depois do exame $(\mathrm{M}=66,8 ; d p=8,0)$. $\mathrm{O}$ teste Wilcoxon revelou diferenças significativas entre os dois momentos $(Z=-2,53 ; p=0,01)$ indicando que o apego materno-fetal foi mais intenso após o exame do que antes do exame.

TABELA 2

Média, Desvio Padrão e Escores Mínimos e Máximos na Escala de Apego Materno-Fetal

\begin{tabular}{lccccc}
\hline & $\mathrm{N}$ & Mínimo & Máximo & $\mathrm{M}$ & $\mathrm{Dp}$ \\
\cline { 2 - 6 } Antes do exame & 11 & 44 & 74 & 61 & 7,82 \\
Depois do exame & 11 & 51 & 77 & 66,81 & 8,02 \\
\hline
\end{tabular}




\section{DISCUSSÃO}

Os resultados do presente estudo revelaram que, de forma geral, a ultrassonografia influenciou nas impressões e sentimentos da gestante sobre o bebê, sobre a relação materno-fetal, a maternidade e o apego mãe-feto. Quanto ao primeiro eixo, que envolveu as impressões e sentimentos das gestantes sobre o bebê, percebeu-se que antes da realização do exame as gestantes revelaram uma imagem mental bastante incipiente sobre o bebê, além de algumas nunca terem imaginado quaisquer dados sobre o bebê. Sabe-se que o primeiro trimestre de gravidez é um momento em que a mulher está mais voltada para si mesma e para seu próprio estado gravídico do que para o bebê, propriamente dito. Já no segundo trimestre é esperado que as mães imaginem mais sobre o bebê e criem até mais expectativas a seu respeito (Cramer, 1993; Missonier \& Solis-Ponton, 2004; Raphael-Leff, 1991, 1997; Stern, 1991). Na medida em que grande parte das participantes deste estudo se encontrava no final do primeiro trimestre do ciclo gravídico, poder-se-ia pensar que a isto se deve a postura de não imaginar o bebê ainda como muito real ou imaginá-lo recém iniciando seu desenvolvimento. No entanto, esta hipótese entra, parcialmente, em descrédito ao observarmos que logo após o exame, passada então, no máximo, uma hora, as gestantes passaram a referir impressões de um bebê mais concreto e real, além de bastante desenvolvido e com um nível de formação mais avançado do que esperavam. Podemos pensar então que as gestantes estavam, primeiramente, demonstrando uma visão sobre o desenvolvimento do bebê conforme a evolução normal da gravidez, e que a ultrassonografia, ao mostrar a imagem do bebê em tempo real e dinâmico, influenciou a imagem materna sobre o bebê, acelerando este processo.

Após três semanas, as impressões das gestantes sobre o bebê se referiram a uma imagem ainda mais real e autônoma dele, salientando gostos próprios, comunicações e até capacidade do bebê para interferir nos hábitos maternos. Pode-se dizer, então, que a intensificação da ideia de um bebê mais concreto e real deve-se, a além do fator desenvolvimental/temporal, aos efeitos do exame que, conforme Milne e Rich (1981), seguem também sendo elaborados, isto é, processados e significados de acordo com as vivências singulares de cada mãe. Além disso, o bebê, depois de três semanas do exame, foi visto como estando bem maior e mais desenvolvido do que no dia da ultrassonografia, o que revela que este espaço de tempo foi suficiente para representar psiquicamente um processo dinâmico de evolução, seja para imaginar mais o bebê e/ou para elaborar a experiência como um todo.

As impressões das gestantes também foram baseadas em características físicas imaginadas para o bebê, as quais, antes da ultrassonografia, partiam somente de atributos de um/ou de ambos os genitores, e características emocionais, formadas nitidamente de desejos das gestantes em relação ao bebê. Já após o exame, passaram a conter também alguns dados informacionais decorrentes da própria ultrassonografia. Milne e Rich (1981) revisaram ideias acerca da formação da imagem mental e apontaram que esta englobaria as imagens de memória - que seriam constructos mentais que se formam a partir da percepção de algo - e as imagens imaginárias - que nada têm a ver com o percebido e sim com os elementos internos e fantasiosos do indivíduo. Pode-se entender que a ultrassonografia propicia a evocação de imagens de memória e também de imagens imaginárias, ou seja, é um estímulo que atinge a percepção, evoca memórias e acessa afetos, acabando por influenciar a ideia da mãe sobre o bebê. Antes do exame, a imagem materna pareceu mais imaginária, uma vez que não contava com estímulos concretos/perceptivos e esteve então relacionada a elementos internos e conhecidos, os genitores, fisicamente representados pelos atributos e emocionalmente pelo desejo. O bebê ainda não real, não existindo por si, como já foi discutido, e representando uma extensão dos pais (Ramona-Thieme, 1995) só poderia ser imaginado a partir dos genitores e seus desejos.

Durante e depois do exame, as impressões sobre as características físicas e emocionais do bebê foram justificadas, parcialmente, com dados do exame, mas ainda pode-se perceber uma mistura com os desejos/expectativas das gestantes em relação ao bebê. É como se as imagens do exame tivessem sido "utilizadas" para confirmar desejos e/ou fantasias que já existiam no mundo interno das gestantes. Já três semanas depois do exame, algumas das impressões das gestantes sobre as características físicas do bebê referidas foram justificadas com base em dados mais concretos do exame. Além disto, a maioria revelou uma mistura ainda mais indiscriminada desses dados às ideias imaginárias e fantasiosas a respeito do bebê. Não podemos ignorar a influência dos dados do exame na construção da imagem mental materna sobre o bebê, porém percebeu-se que o bebê na ultrassonografia parece ser visto mais com os olhos do desejo e do inconsciente materno do que com os da realidade concreta; as mães vêem o que precisam, querem e podem ver e não objetivamente o que está sendo mostrado (Caron, 2000). 
Afora as impressões e concernente mais especificamente aos sentimentos das mães, predominaram, antes do exame, sentimentos de incerteza e medo em relação ao desenvolvimento do bebê, seja através de dúvidas sobre o número de bebês que estavam sendo gestados e/ou pelo medo da ocorrência de alguma anormalidade fetal. Essa incerteza, conforme Lumley (1980), foi descrita por dois terços das gestantes de primeiro trimestre da sua pesquisa, que demonstraram que o bebê ainda não significava uma pessoa conhecida e real. Assim, pode-se compreender que a ideia de incerteza quanto à caracterização do bebê nos remete a este início ainda indiscriminado na mente da mãe. Já em seguida ao exame, as gestantes se mostram mais esclarecidas sobre o bebê. A ultrassonografia parece ter propiciado a algumas gestantes conhecer mais o bebê e se sentir mais apropriada da sua imagem.

Após três semanas, algumas gestantes se mostraram seguras, mas outras revelaram ainda incerteza e medo de que o bebê venha a ter algum problema. Essa maior ou menor ligação com o exame na construção de uma imagem mental do bebê parece estar mais relacionada à concepção inconsciente que as mães têm sobre os bebês. Se estas acreditarem que de fato pode ou deve haver algum problema, a ultrassonografia pode até amenizar o seu medo e a sua crença nesta realidade, mas em seguida estes podem voltar a fazer parte dos pensamentos e sentimentos das gestantes; e, vice-versa, se houver uma maior tranquilidade e/ou até negação quanto à possibilidade da ocorrência de uma anormalidade fetal, as respostas do exame, por mais superficiais e/ou imprecisas que sejam darão conta de assegurar a saúde do bebê. Por fim, as impressões e sentimentos das gestantes sobre o bebê pareceram ter sido norteados pelas informações transmitidas na ultrassonografia; porém, o que mais parece contribuir para a imagem mental materna do bebê são os seus próprios desejos, necessidades e medos, a sua realidade psíquica e a concepção inconsciente de cada mãe sobre cada bebê.

Quanto ao segundo eixo temático, concernente às implicações da ultrassonografia na relação mãe-bebê, os resultados também revelaram mudanças após a realização do exame. Os dados antes do procedimento mostraram que algumas gestantes ainda não tinham estabelecido um contato mais direto com o bebê. Além do fator desenvolvimental, que diz que no primeiro trimestre a mãe recém está começando a desviar a atenção de si para o bebê (Maldonado, 1997; Raphael-

-Leff, 1991, 1997), não há como desconsiderar outros fatores de ordem individual que podem estar implicados, como uma dificuldade em perceber e imaginar a existência do bebê. Lumley (1980) referiu que conceber o bebê como mais real está diretamente relacionado ao estabelecimento da relação mãe-bebê.

Ainda em relação à literatura que aponta, neste primeiro trimestre, um movimento da mãe mais voltado à adaptação de si com seu estado gravídico (Cramer, 1993), pode-se pensar que as mães deste estudo que verbalizaram uma relação ainda inexistente estão precisando, então, utilizar este período inicial para tal adaptação. Já outras passam mais rapidamente por este período e/ou estabelecem uma relação com o bebê mesmo que ainda misturado consigo, como aquelas que referiram contato através do cuidado com a gravidez. Algumas se mostraram ainda mais diretamente conectadas, relatando formas diretas de interação, seja por conversas, toque e/ou pensamentos.

Na relação mãe-bebê durante e após o exame e três semanas depois, apareceu o surgimento e/ou intensificação de sentimentos de afeto e de posse pelo bebê, elementos que não tinham sido referidos antes do exame por várias gestantes e que talvez expliquem o início de uma visão mais separada de si e do bebê. É como se o exame, ao mostrar o bebê de fato, inviabilizasse reações de indiferença, além de propiciar para aquelas gestantes que ainda não tinham uma imagem mental do bebê, um estímulo real sobre o qual elas poderiam construir uma representação estética e, então, começassem a lhe dirigir sentimentos de afeto. Porém, o sentimento de posse, que também foi evidente em alguns relatos, embora mostre o reconhecimento da existência de outro que não sou eu, é ainda de um outro que é meu, nos dando ainda a ideia da relativa extensão e indissociabilidade entre mãe e bebê. Nesta mesma direção apareceu a intenção em aumentar os cuidados consigo mesmas, pois seria através de si que as gestantes contatariam com o bebê.

A ultrassonografia parece ter tido uma influência positiva, especificamente, sobre o fato de as gestantes terem intensificado os cuidados consigo mesmas, preocupando-se com a alimentação e sono, até uma maior adesão às recomendações médicas, como realização de exames e controle de atividades, corroborando com outras pesquisas referidas por Baillie e cols. (1997).

A dimensão de maior realidade do bebê incita a ideia de que o bebê está de fato ali, está desenvolvido e é capaz, então, de reagir aos seus comportamentos. Logo, não se pode dizer que a relação mãe-bebê não se torna mais intensificada simplesmente porque o 
bebê se tornou mais real para a mãe, mas também porque esta se sentiu mais real para o bebê. Ademais, a relação mãe-bebê depois de três semanas apareceu muito ligada às lembranças das imagens do bebê no aparelho de ultrassonografia. Aquele é o bebê que elas conhecem, o que elas viram; aquele bebê visto no exame é o seu bebê, é o bebê que elas passam a imaginar. Pode-se dizer, então, que é como se o exame personificasse o bebê, lhe dando um corpo e isso parece facilitar a relação da mãe com o bebê.

Houve também algumas gestantes que verbalizaram não terem percebido a influência da ultrassonografia na sua relação com o bebê. Percebe-se que as duas gestantes que referiram esse sentimento demonstravam formas de relação polarizadas, uma revelando que desde sempre estabeleceu intensa interação com o bebê e outra que parecia ainda não ter estabelecido nenhum nível de contato. Assim, pode-se pensar que a ultrassonografia serviria mais para intensificar sentimentos dentro de um mesmo nível ou levar a uma resolução de sentimentos mais ambivalente, mas não para acarretar transformações expressivas nos sentimentos e/ou na forma de relação.

Por fim, em relação ao terceiro e último eixo temático, as implicações da ultrassonografia nos sentimentos maternos também se fizeram presentes. Antes do exame, estes sentimentos apareceram como ainda inexistentes em alguns relatos, enquanto que naqueles nos quais se fizeram presentes, mostraram-se de difícil explicação e definição por parte das gestantes. Apesar de definidos com uma predominância de sentimentos positivos, negativos ou ambivalentes, percebem-se diversas expressões de incerteza, como se ainda se tratasse de um sentimento incipiente, novo, e que por isso se tornava difícil de traduzir e transmitir.

Em contrapartida, houve relatos que destacaram mais diretamente o bebê, mas mesmo nestes, o sentimento preponderante foi o de estranhamento, o qual, conforme Rubin (1975) é próprio da gestação e decorre da singularidade e da intensidade da gravidez na vida da mulher, que a faz se sentir estranha em relação ao mundo externo. Com base nos autores (Maldonado, 1997; Raphael-Leff, 1997), podemos compreender a postura de algumas das gestantes do presente estudo quando não fazem referência a sentimentos maternos de forma definida e relacionada tão diretamente ao bebê. Para estes autores, no primeiro trimestre de gestação, os sentimentos de maternidade estão ainda dirigidos a uma adaptação à condição de gravidez, deixando que o lugar do bebê exista mais a partir do se- gundo trimestre. Porém, durante e logo após o exame, as gestantes já relataram uma ideia de concretização da gravidez, da maternidade e do próprio bebê. Algumas se disseram, ainda, mais conscientes sobre a realidade de ter agora um ser dependente de si. Este achado corrobora os apresentados por Sioda (1984) em um estudo sobre os efeitos psicológicos da ultrassonografia, os quais mostraram que as gestantes, logo após o exame, reportaram se dar conta de que eram de fato mães e que esse sentimento parecia decorrer da consciência de que o bebê existia e estava vivo.

As gestantes referiram, ainda, a partir das imagens ultrassonográficas, imensa satisfação pela sua natureza feminina e pela possibilidade de gestar. Isso reflete um sentimento de completude, de cumprimento do papel social e psíquico de mãe e mulher. Szejer e Stewart (1997) complementam estas ideias dizendo da natureza da gestação de um corpo dentro do outro, envolvidos por uma só pele, e as verbalizações das gestantes revelam um sentir-se em evidência diante da condição "espaçosa e competente" de carregar e gestar alguém dentro de si.

A partir destes dados pode-se começar pensando a respeito do porquê, antes do exame, os sentimentos sobre a maternidade estavam mais vagos e menos definidos e, logo em seguida, depois de no máximo duas horas, passaram a mais concretos. Por que somente depois do exame muitas das gestantes falam da satisfação de gestar? Por que só depois muitas referem consciência sobre o bebê se antes elas já sabiam que estavam grávidas? Saber da gravidez, mesmo por uma prova concreta, não parece ser suficiente para que muitas gestantes se sintam grávidas, e sim só podem se sentir como tal através da prova concreta da existência do bebê. É também através da concretização do bebê que elas referem à satisfação pela natureza feminina; talvez seja só assim que elas podem se sentir mulheres, mães, quando veem no seu corpo um outro corpo. Elas tiveram essa prova com a ultrassonografia e, para a maioria delas, esta foi a primeira prova. Assim, parece-nos que a consciência da gestante sobre a existência real do bebê contribui para que os sentimentos maternos sejam definidamente estabelecidos.

Após três semanas do exame, os sentimentos de maternidade apareceram nos relatos das gestantes mais intensificados que antes, mesmo entre aquelas que tinham referido antes do exame ainda não tê-los percebido, passaram a se perceber "um pouco mais mães". É possível notar, diferentemente do momento logo após o exame, a ausência de conteúdos de concretização do bebê, passadas três semanas. Parece que 
a consciência da existência real do bebê adquirida na ultrassonografia acabou por acionar os sentimentos maternos de forma ainda mais dirigida ao bebê, traduzindo-os sob a forma de preocupação com ele e com o papel materno.

Apesar destas novas elaborações, decorrentes em parte do exame realizado, algumas gestantes mostraram que o sentimento materno ainda estava sendo sentido como confuso, e que seria diferente do que será futuramente após o nascimento do bebê. Klaus e Kennel (1992) e Rubin (1975) nos falam da gestação como um momento de reformulação de identidade para a mulher, durante o qual as relações podem ser reconfiguradas e o espaço psicológico interno reordenado. Logo, o sentimento de confusão referido pelas participantes do presente estudo pode também ter raízes neste movimento de reestruturação psíquica, que confere à mulher durante a gravidez um estado de transição em diversos aspectos da sua vida: pessoal, conjugal, econômico e social.

Quanto ao apego materno-fetal, os resultados foram significativamente mais altos após a ultrassonografia do que antes do exame. Estes resultados corroboram os achados de outros estudos que, através de entrevistas (Fletcher \& Evans, 1983; Milne \& Rich, 1981), questionários (Kohn \& cols., 1980), diferentes escalas (Kovacevic, 1993; Michelacci \& cols., 1988) e da própria escala utilizada no presente estudo (Caccia \& cols., 1991) também verificaram uma intensificação no apego mãe-bebê após a realização da ultrassonografia De modo geral, estes autores salientaram que o conhecimento sobre o bebê e a possibilidade de visualizá-lo provoca um aumento de bem-estar da mãe, além do aumento de sentimentos de afeto pelo bebê, o que, por sua vez, propicia uma relação mãe-bebê de melhor qualidade.

Assim, através dos dados do presente estudo, constata-se que, após ver a imagem do bebê no monitor de ultrassonografia e de ter notícias sobre seu bebê, as gestantes passaram a se vincular mais ao bebê e, por conseguinte, a emitir com mais frequência comportamentos de apego em relação a ele. Essa reação pode provir principalmente da concretização da gravidez e do bebê (Verny, 1986; Villeneuve \& cols., 1988), ocorrida depois do exame de ultrassonografia. No presente estudo, diz-se que é como se com o passar das semanas, o bebê fosse reconhecido como mais personalizado, sendo, portanto, mais "merecedor" da interação materna. O aumento do apego fez, então, com que as gestantes provavelmente dirigissem ao bebê mais frequentemente comportamentos de afeto e interação, como conversar mais com o bebê, imaginar mais ele e com ele, escolher o nome, aspectos estes avaliados pela escala respondida pelas gestantes.

\section{CONSIDERAÇÕES FINAIS}

Os resultados do presente estudo revelaram que o bebê passou a ser visto como mais real e personalizado após a realização da ultrassonografia e isso parece ter influenciado na relação mãe-bebê, intensificando os comportamentos de interação da dupla e até aumentando o nível de apego materno-fetal. A maternidade se tornou mais evidente para a gestante, que passou a se sentir mais envolvida no papel materno de cuidado e proteção ao bebê.

Vale ressaltar que os sentimentos decorrentes do exame não substituíram aqueles provenientes das fantasias maternas sobre o bebê e, em alguns casos, estimularam ainda mais esse processo imaginativo, servindo até como justificativa para a mãe acreditar que o bebê seria de determinada maneira. Assim, as gestantes parecem enxergar a imagem do bebê, a partir mais de representações psíquicas do que de dados concretos obtidos no exame. Diz-se, com isso, que o exame pode, sim, promover a intensificação do vínculo mãe-bebê e antecipar a eclosão de sentimentos, porém não leva a modificações radicais na dinâmica da relação mãe-bebê ou na representação psíquica daquele bebê para a mãe.

Por fim, a ultrassonografia é hoje um importante recurso diagnóstico do pré-natal, considerado já de rotina no nosso país, porém por vezes não recebe a importância merecida, do ponto de vista emocional. Cabe aos profissionais da saúde defender e lembrar a todos os envolvidos que este exame acarreta implicações emocionais em qualquer gestante que o realiza, sendo por isso, necessário proferir um ambiente de qualidade, não somente técnica, mas também emocional.

\section{REFERÊNCIAS}

Baillie, C., Mason, G., \& Hewison, J. (1997). Scanning for pleasure. British Journal of Obstetrics and Gynaecology, 104, 11231124.

Berryman, J. (1993). Pregnancy after 35: A preliminary report on maternal-fetal attachment. Journal of Reproductive and Infant Psychology, 11, 169-174.

Boukydis, C., Treadwell, M., Delaney-Black, V., Boyes, K., King, M., Robinson, T., \& Sokol, R. (2006). Women's responses to ultrasound examinations during routine screens in an obstetric clinic. Journal of Ultrasound in Medicine, 25(6), 721- 728.

Caccia, N., Johnson, J., Robinson, G., \& Barna, T. (1991). Impact of prenatal testing on maternal-fetal bonding: Chorionic villus sampling versus amniocentesis. American Journal Obstetric Gynecology, 4, 1122-1125. 
Caron, N. (2000). O ambiente intra-uterino e a relação materno-fetal. Em N. Caron (Org.), A relação pais-bebê: Da observação à clínica (pp. 119-134). São Paulo: Casa do Psicólogo.

Chudleigh, P., \& Pearce, J. (1992). Obstetric ultrasound. Londres: Churchill Livingstone.

Courvoisier, A. (1985). Échographie obstétricale et fantasmas. Neuropsychiatrie de l'Enfance et de l'Adolescence, 33, 103-105.

Cramer, B. (1993). Profissão bebê. São Paulo: Martins Fontes.

Cranley, M. (1981). Development of a tool for the measurement of maternal attachment during pregnancy. Nursing Research, 30, 281-284.

Feijó, M. (1999). Validação brasileira da Maternal-Fetal Attachment Scale. Arquivos Brasileiros de Psicologia, 51, 52-62.

Fletcher, J., \& Evans, M. (1983). Maternal bonding in early fetal ultrasound examinations. New England Journal of Medicine, 308, 392-393.

Fonseca, M., Magalhães, J., Papich, H., Dias, R., \& Schimidt, A. (2000). Ultra-sonografia em obstetrícia: Explorando um novo mundo. Em N. Caron (Org.), A relação pais-bebê: Da observação à clínica (pp. 97-118). Porto Alegre: Casa do Psicólogo.

Gomes, A., \& Donelli, T. (2001). Entrevista de história obstétrica da gestante. Porto Alegre: Instituto de Psicologia - UFRGS. Instrumento não publicado.

Gomes, A., \& Piccinini, C. (2001). Entrevista sobre a ultra-sonografia obstétrica e a relação materno-fetal. Porto Alegre: Instituto de Psicologia - UFRGS. Instrumento não-publicado.

Grace, J. (1989). Development of maternal-fetal attachment during pregnancy. Nursing Research, 38, 228-232.

Grupo de Interação Social, Desenvolvimento e Psicopatologia (1998a). Termo de Consentimento Livre e Esclarecido. Porto Alegre: Instituto de Psicologia - UFRGS. Instrumento não-publicado.

Grupo de Interação Social, Desenvolvimento e Psicopatologia (1998b). Ficha de dados demográficos da gestante. Porto Alegre: Instituto de Psicologia - UFRGS. Instrumento não-publicado.

Klaus, M., \& Kennel, J. (1992). Pais/bebê: A formação do apego. Porto Alegre: Artes Médicas.

Kohn, C., Nelson, A., \& Weiner, S. (1980). Gravida's response to realtime ultrasound fetal image. Journal of Obstetric, Gynecology and Neonatal Nursing, 9, 77-80.

Kovacevic, M. (1993). The impact of fetus visualization on parent's psychological reactions. Pre and Perinatal Psychology Journal, 8, 83-93.

Laville, C., \& Dionne, J. (1999). A construção do saber: Manual de metodologia da pesquisa em ciências humanas. Porto Alegre: Artes Médicas.

Lumley, J. (1980). The image of the fetus in the first trimester. Birth and the Family Journal, 7(1), 5-14.

Maldonado, M. T. P. (1997). Psicologia da gravidez. Petrópolis: Vozes.

Michelacci, L., Fava, G., Grandi, S., Bovicelli, L., Orlandi, C., \& Trombini, G. (1988). Psychological reactions to ultrasound examination during pregnancy. Psychoterapy Psychossomatic, 50, 1-4.

Milne, L., \& Rich, U. (1981). Cognitive and affective aspects of the responses of pregnant women to sonography. Maternal Child Nursing Journal, 10, 15-39.
Missonnier, S., \& Solis-Ponton, L. (2004). Parentalidad y embarazo. Convertirse en madre, convertirse en padre: Las interacciones entre los padres y su hijo antes del nacimiento. Em SolisPonton, L. (Org.), La parentalidad: Desafios para el tercer milenio (pp. 75-92). Cidade do México: El Manual Moderno.

Nicol. M. (2007). Vulnerability of first time expectatnt mothers during ultrasound scans: An evaluation of the external pressures that influence the process of informed choice. Health Care Women International, 28(6), 525-533.

Piontelli, A. (2000). Is there something wrong? The impact of technology in pregnancy. Em Raphael-Leff, J. (Org.), 'Spilt milk' perinatal loss \& breakdown (pp. 39-52). Londres: Institute of Psychoanalysis.

Pretorius, D., Gattu, S., Ji, E., Hollenbach, K., Newton, R., Hull, A., Carmona, S., Dágostini, D., \& Nelson, T. (2006). Preexamination and postexamination assessment of parental-fetal bonding in patients undergoing 3-/4-dimensional obstetric ultrasonography. Journal of Ultrasound in Medicine, 25(11), 14111421.

Quayle, J., Isfer, E., \& Zugaib, M. (1991). Considerações acerca das representações associadas ao diagnóstico pré-natal. Revista de Ginecologia e Obstetrícia, 2, 34-38.

Ramona-Thieme, M. (1995). Becoming a mother: Research on maternal identity from Rubin to the present. New York: Spring Publishing.

Raphael-Leff, J. (1991). Psychological processes of childbearing. Londres: Chapman \& Hall.

Raphael-Leff, J. (1997). Gravidez: A história interior. Porto Alegre: Artes Médicas.

Robson, C. (1995). Real World Research: A resource for social scientists and practitioner-researchers. Oxford, UK: Blackwell.

Rubin, R. (1975). Maternal tasks in pregnancy. Maternal-Child Nursing, 4, 143-153.

Sioda, T. (1984). Psychological effects of cardiotocographic and ultrasonographic examinations in pregnancy and labour on the mother. Ginekologia Polska, 55, 653-660.

Soulé, M. (1987). O filho da cabeça, o filho imaginário. Em T. Brazelton, B. Cramer, L. Kreisler, R. Schappi, \& M. Soulé, A dinâmica do bebê (pp. 132-170). Porto Alegre: Artes Médicas.

Stake, R. (1994). Case studies. Em N. Denzin, \& Y. Lincoln (Orgs.), Handbook of qualitative research (pp. 236-247). London: Sage.

Stern, D. (1997). A constelação da maternidade. Porto Alegre: Artes Médicas.

Szejer, M., \& Stewart, R. (1997). Nove meses na vida da mulher. São Paulo: Casa do Psicólogo.

Van der Zalm, J., \& Byrne, P. (2006). Seeing baby: Women's experience of prenatal ultrasound examination and unexpected fetal diagnosis. Journal of Perinatology, 26(7), 403-408.

Verny, T. (1986). The psycho-technology of pregnancy and labor. Pre and Perinatal Psychology, 1, 31-49.

Villeneuve, C., Laroche, C., Lippman, A., \& Marrache, M. (1988). Psychological aspects of ultrasound imaging during pregnancy. Canadian Journal of Psychiatry, 33, 530-535.

Recebido: 11/08/2007

Última revisão: 19/06/2010 Aceite final: 20/07/2010 


\section{Notas:}

${ }^{1}$ Este artigo é baseado em parte da dissertação de mestrado de Aline Grill Gomes, realizada e apresentada no Curso de Pós-Graduação em Psicologia do Desenvolvimento da Universidade Federal do Rio Grande do Sul sob a supervisão de Cesar Augusto Piccinini.

${ }^{2}$ Na codificação da escala, seguiu-se o procedimento comumente relatado na literatura (Berryman, 1993; Caccia e cols., 1991; Chudleigh \& Pearce, 1992) de adaptar a escala em função da idade gestacional das participantes. Em função disto, foram excluídos itens que investigam os movimentos fetais $(3,9,16,17,20,21,24)$ quando respondidos pelas gestantes com idade gestacional acima de 20 semanas (G4, G5 e G7) quando é possível se perceber os movimentos fetais.

\section{Sobre os autores:}

Aline Grill Gomes: Psicóloga, psicoterapeuta psicanalítica (formada pelo Instituto de Ensino e Pesquisa em Psicoterapia - IEPP), Mestre e Doutora em Psicologia do Desenvolvimento pelo Curso de Pós-graduação em Psicologia do Desenvolvimento da Universidade Federal do Rio Grande do Sul, sob a orientação do Prof. Dr. Cesar Piccinini.

Cesar Augusto Piccinini: Doutor e pós-doutor pela University College of London (Inglaterra), pesquisador do CNPq e professor do Curso de Pós-graduação em Psicologia do Desenvolvimento da Universidade Federal do Rio Grande do Sul.

Endereço para correspondência: Universidade Federal do Rio Grande do Sul - Instituto de Psicologia - Rua Ramiro Barcelos, 2600/111 - 90035-006 Porto Alegre/RS. Endereço eletrônico: algrill7@ yahoo.com.br. 